09

\title{
Реализация физических подходов к конструированию функциональных металлодиэлектрических систем на основе опалов в фотонике
}

\author{
(C) С.Д. Ханин ${ }^{1}$, А.И. Ванин ${ }^{2}$, Ю.А. Кумзеров ${ }^{2,3}$, В.Г. Соловьев ${ }^{1,2}$, А.В. Цветков ${ }^{2}$, М.В. Яников ${ }^{2}$ \\ ${ }^{1}$ Военная академия связи имени Маршала Советского Союза С.М. Буденного, \\ 194064 Санкт-Петербург, Россия \\ ${ }^{2}$ Псковский государственный университет, \\ 180000 Псков, Россия \\ ${ }^{3}$ Физико-технический институт им. А.Ф. Иоффре РАН, \\ 194021 Санкт-Петербург, Россия \\ e-mail: solovyev_v55@mail.ru
}

Поступило в Редакцию 14 сентября 2021 г.

В окончательной редакции 13 октября 2021 г.

Принято к публикации 16 октября 2021 г.

\begin{abstract}
Показаны возможности практической реализации физических подходов к созданию металлодиэлектрических фотонно-кристаллических систем на основе опалов, позволяющих управлять распространением электромагнитных волн. Реализуемые подходы базируются на эффектах возбуждения поверхностных плазмон-поляритонов, способных распространяться вдоль границ раздела металл-диэлектрик в плазмоннофотонных слоистых гетероструктурах, и модификации фотонно-энергетической структуры нанокомпозита в результате диспергирования в матрице опала серебра. Представлены экспериментальные результаты, указывающие на возникновение аномального пропускания и поглощения света в плазмонно-фотонных гетероструктурах, а также на асимметричную форму кривых в спектрах отражения нанокомпозитов, что связано с резонансом Фано.
\end{abstract}

Ключевые слова: фотонные кристаллы, опалы, поверхностные плазмон-поляритоны, металлодиэлектрические системы, резонанс Фано.

DOI: 10.21883/JTF.2022.02.52020.255-21

\section{Введение}

Присущее развитию электроники и фотоники динамичное нарастание подлежащих освоению физических знаний актуализирует проектирование устройств на физическом уровне, что находит свое отражение в научной литературе последних лет (например, [1]). В настоящей работе данный подход используется применительно к функциональным металлодиэлектрическим системам фотоники.

В ряду функциональных материалов фотоники, позволяющих управлять потоками электромагнитного (ЭМ) излучения за счет направленной модификации спектров пропускания и отражения света, важное место занимают фотонные кристаллы (ФК) [2,3], обладающие пространственной периодичностью показателя преломления (ПП), что приводит к возникновению запрещенных энергетических состояний для света с длиной волны, сопоставимой с периодом структуры - фотонных запрещенных зон (ФЗ3).

В основу разработки многих устройств современной фотоники положены плазмонно-фотонные гетерокристаллы (ПФГК) [4], представляющие собой различные комбинации слоев ФК, находящихся в контакте с тонкими металлическими пленками. Повышение функциональных возможностей таких систем по сравнению с обычными ФК осуществляется за счет переноса энергии вдоль границы металл-диэлектрик поверхностными плазмон-поляритонами (ППП) [5], движением которых, согласно предсказаниям теории [6-8], можно управлять. Эти эффекты представляют интерес для создания волноводных структур в СВЧ [9], терагерцевом [10] и видимом [11] диапазонах, новых типов лазеров [12] и светодиодов [13], волоконно-оптических рефрактометров [14], сенсоров $[15,16]$, оптических логических элементов [17], высокоскоростных оптических каналов передачи данных [18], а также для снижения потерь в брэгговских решетках [19], уменьшения размеров, повышения рабочей частоты и эффективности устройств обработки и передачи информации [20].

При проектировании плазмонно-фотонных приборов следует иметь в виду, что кроме ППП, распространяющихся вдоль границы металл-диэлектрик, при выполнении определенных условий (как правило, при нормальном падении света на границу „металл-ФК“ [21]) возникают таммовские оптические состояния в виде стоячих поверхностных волн, которые не переносят энергию вдоль поверхности и могут быть экспериментально обнаружены по узкому пику пропускания в ФЗ3 ФК [22].

Другой подход к конструированию функциональных металлодиэлектрических систем с заданными свойства- 
ми состоит в модифицировании фотонной энергетической структуры образца посредством диспергирования металла в диэлектрической матрице опала.

С целью реализации обоих подходов в настоящей работе проведены экспериментальные исследования модельных слоистых металлодиэлектрических систем, в состав которых входили серебро, представляющее собой основной плазмонный материал, имеющий минимальные потери в видимой и ближней инфракрасной областях спектра [12], а также ФК на основе „массивных“ синтетических опалов, состоящих из одинаковых сфер (глобул) диаметром порядка сотен нанометров [23], которые могут выступать в роли трехмерных ФК [24-28].

\section{1. Использование ППП для модификации оптических свойств ПФГК на основе опалов}

Как известно, для возбуждения ППП используются специальные экспериментальные методы [11], разработанные А. Отто, Э. Кречманном и другими исследователями. В одном из этих методов создается периодический рельеф на границе раздела металл-диэлектрик, обеспечивающий условия одновременного выполнения законов сохранения энергии и импульса при возбуждении ППП. Такой периодический рельеф был реализован нами при нанесении пленки металла на периодически расположенные опаловые глобулы (рис. 1) [29]. В этом случае при падении света на решетку с периодом $a$ закон сохранения импульса можно записать в виде [11]:

$$
\beta=k_{x}+2 \pi l / a,
$$

где $\beta$ и $k_{x}-$ проекции волнового вектора ППП и падающей световой волны на границу раздела соответственно, $l$ - целое число.

Для получения границ раздела профилированный слой серебра-монослой опаловых глобул и профилированный слой серебра-воздух, обеспечивающих соответствие морфологии связного металлического покрытия особенностям поверхности исходного ФК, использовался метод магнетронного распыления вещества на установке ATC ORION SERIES SPUTTERING SYSTEM. Методы приготовления и исследования образцов ПФГК

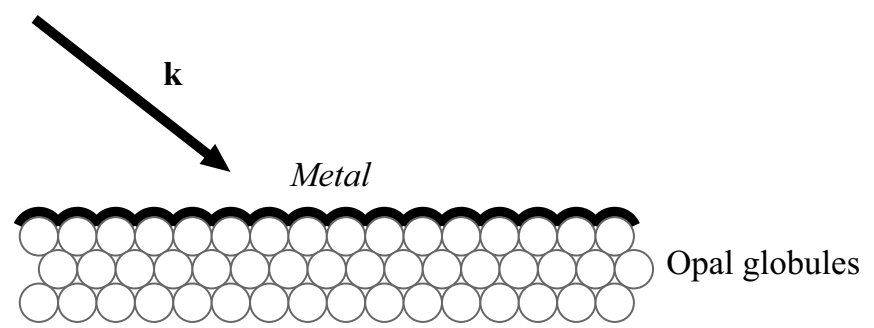

Рис. 1. Использование периодического рельефа на границе раздела сред металл-диэлектрик для возбуждения ППП (k волновой вектор падающей электромагнитной волны) [29].

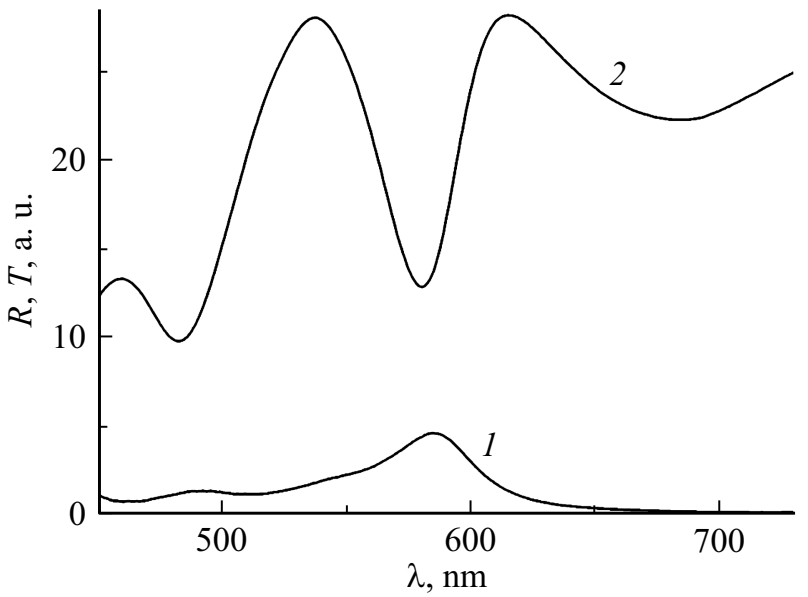

Рис. 2. Спектры пропускания (1) и отражения (2) гибридного плазмонно-фотонного кристалла $\mathrm{Ag} / \mathrm{SiO}_{2} / \mathrm{Ag} / \mathrm{ML} / \mathrm{Ag}$ при угле падения света $\theta=16^{\circ}$.

$\mathrm{Ag} / \mathrm{SiO}_{2} / \mathrm{Ag} / \mathrm{ML} / \mathrm{Ag}$, сформированных нанесением на стеклянную подложку слоев серебра $(\mathrm{Ag})$, диэлектрика $\left(\mathrm{SiO}_{2}\right)$ и монослоя (ML) опаловых глобул в указанной последовательности, описаны в работах [30-32].

Возбуждение ППП приводит к появлению в спектрах пропускания таких образцов ПФГК $\mathrm{Ag} / \mathrm{SiO}_{2} / \mathrm{Ag} / \mathrm{ML} / \mathrm{Ag}$ максимумов, отвечающих аномальному пропусканию света (extraordinary transmission - EOT). При этом, как видно из рис. 2 , спектральное положение этих максимумов коррелирует с положением глубоких минимумов в спектрах отражения исследованных образцов (в данном случае они находятся вблизи длин волн $\lambda_{1}=489 \mathrm{~nm}$ и $\left.\lambda_{2}=584 \mathrm{~nm}\right)$. Последнее как раз и указывает на то, что энергия падающей ЭМ волны частично расходуется на возбуждение ППП. По-видимому, в указанных областях спектра условие (1) выполняется для границ раздела профилированной металлической пленки с воздухом (на длине волны $\lambda_{1}$ ) и твердым диэлектриком (на длине волны $\lambda_{2}$ ).

На рис. 3 представлена угловая дисперсия спектрального положения длинноволнового максимума, отвечающего аномальному пропусканию гибридного плазмоннофотонного кристалла $\mathrm{Ag} / \mathrm{SiO}_{2} / \mathrm{Ag} / \mathrm{ML} / \mathrm{Ag}$. Положение коротковолнового максимума EOT, как показывает эксперимент, практически не зависит от угла падения света.

Закон дисперсии ППП на границе между металлом и диэлектриком с показателем преломления $n$ может быть представлен в виде [11,29]:

$$
\beta^{2}=\left(\omega^{2} n^{2} / c^{2}\right)\left\{1+\left(\omega^{2} n^{2} /\left[\omega_{p}^{2}-\omega^{2}\left(1+n^{2}\right)\right]\right\},\right.
$$

где $c$ - скорость света в вакууме, а плазменная частота для серебра $\omega_{p}$ существенно превышает частоту ЭМ волны $\omega=2 \pi c / \lambda$. Оценка эффективного ПП монослоя опаловых глобул в реализуемом ПФГК по формулам (1) и (2) с использованием полученных в эксперименте длин волн $\lambda_{1}$ и $\lambda_{2}$, соответствующих максимумам аномального пропускания при малом угле падения света, 


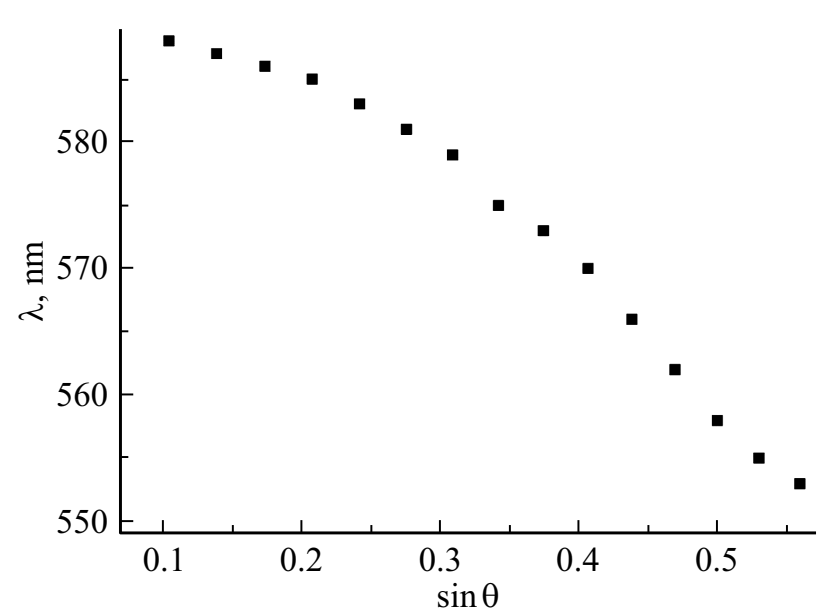

Pис. 3. Угловая дисперсия спектрального положения длинноволнового максимума ЕОТ гибридного плазмонно-фотонного кристалла $\mathrm{Ag} / \mathrm{SiO}_{2} / \mathrm{Ag} / \mathrm{ML} / \mathrm{Ag}$.

периода $a=D \sqrt{3} / 2 \approx 357 \mathrm{~nm}$ исследуемой двумерной решетки глобул из полиметилметакрилата диаметром $D \approx 413 \mathrm{~nm}[32,33]$ дает значение $n \approx 1.27$. Эта величина несколько меньше расчетного значения эффективного показателя преломления монослоя $\left(n_{\mathrm{eff}} \approx 1.32[32]\right)$, что связано, по-видимому, с неплотной упаковкой опаловых глобул в монослое.

Как показывают наши эксперименты, наряду с аномальным пропусканием света (ЕОТ) в рассматриваемых системах при определенных условиях возникает также интенсивное аномальное оптическое поглощение (extraordinary absorption - EOA) [31,32]. Мы полагаем, что наблюдаемые явления связаны с возбуждением распространяющихся вдоль границ раздела профилированный слой металла-диэлектрик поверхностных плазмонполяритонов двух типов: „светлых“, отвечающих за аномальное пропускание, и „темных“, вызывающих аномальное поглощение.

Для наблюдения аномального поглощения последовательно с монослоем опаловых глобул $\mathrm{Ag} / \mathrm{ML} / \mathrm{Ag}$ в структуру вводился резонатор (интерференционный фильтр) $\mathrm{Ag} / \mathrm{SiO}_{2} / \mathrm{Ag}$, в результате чего создавался ПФГК $\mathrm{Ag} / \mathrm{SiO}_{2} / \mathrm{Ag} / \mathrm{ML} / \mathrm{Ag}$. Подходы к интерпретации спектров пропускания такой слоистой системы и ее составных частей были предложены в работах $[31,32]$.

Если бы плазмонно-фотонный кристалл $\mathrm{Ag} / \mathrm{ML} / \mathrm{Ag}$ и резонатор $\mathrm{Ag} / \mathrm{SiO}_{2} / \mathrm{Ag}$ (с коэффициентами пропускания $T_{1}(\lambda)$ и $T_{2}(\lambda)$ соответственно) преобразовывали ЭМ излучение как два последовательно соединенных независимых пассивных оптических элемента, то для коэффициента пропускания ПФГК $\mathrm{Ag} / \mathrm{SiO}_{2} / \mathrm{Ag} / \mathrm{ML} / \mathrm{Ag}$ имело бы место очевидное равенство: $T_{3}(\lambda)=T_{1}(\lambda) T_{2}(\lambda)$, так что во всей исследованной области спектра отношение $r=T_{3}(\lambda) /\left(T_{1}(\lambda) T_{2}(\lambda)\right)$ равнялось бы единице. Как показывает эксперимент, в действительности это не так: величина $r$ зависит от длины волны, причем спектральная зависимость $r(\lambda)$ (рис. 4, кривая 1 ) демонстрирует глубокие минимумы ЕОА (при 392 и $760 \mathrm{~nm}$ для угла падения $\theta=16^{\circ}$ ), положение которых практически совпадает с минимумами в спектре отражения резонатора (рис. 4, кривая 2) при всех углах падения света на образец.

Интересно отметить, что в контрольных опытах с ПФГК $\mathrm{Ag} / \mathrm{ML} / \mathrm{Ag} / \mathrm{SiO}_{2} / \mathrm{Ag}$ с обратной последовательностью слоев, когда опаловые глобулы контактировали с плоской (а не профилированной, повторяющей морфологию слоя опаловых глобул) серебряной пленкой резонатора, присущих поверхностным плазмон-поляритонам эффектов не наблюдалось. В этом случае монослой опаловых глобул $\mathrm{Ag} / \mathrm{ML} / \mathrm{Ag}$ и интерференционный фильтр $\mathrm{Ag} / \mathrm{SiO}_{2} / \mathrm{Ag}$ действительно работали как два последовательно соединенных независимых пассивных оптических элемента, отношение $r=T_{3}(\lambda) /\left(T_{1}(\lambda) T_{2}(\lambda)\right)$ оказалось близким к единице, а описанные выше заметные эффекты ЕОТ и ЕОА не наблюдались. Это еще раз указывает на важность использования профилированной границы раздела между металлической пленкой и диэлектриком для возбуждения ППП в периодических структурах.

Еще одним свидетельством в пользу сказанного являются экспериментальные результаты, полученные в работе [34], согласно которым ППП не возбуждались в случаях, когда серебро осаждалось на опаловые глобулы не сплошным слоем, а в виде отдельных, далеко отстоящих друг от друга кластеров, что препятствовало „перетеканию“ плазмон-поляритонов.

Заметим, что при замене в ПФГК серебра на золото [32] нам также не удалось наблюдать в спектрах пропускания образцов особенностей, свидетельствующих о возбуждении ППП. Это обстоятельство, по нашему мнению, может быть объяснено сильным поглощением света, обусловленным межзонными переходами в золоте, которые попадают в исследуемую спектральную область, в отличие от соответствующих переходов в серебре $[11,20,35]$. Отметим при этом, что авторы ра-

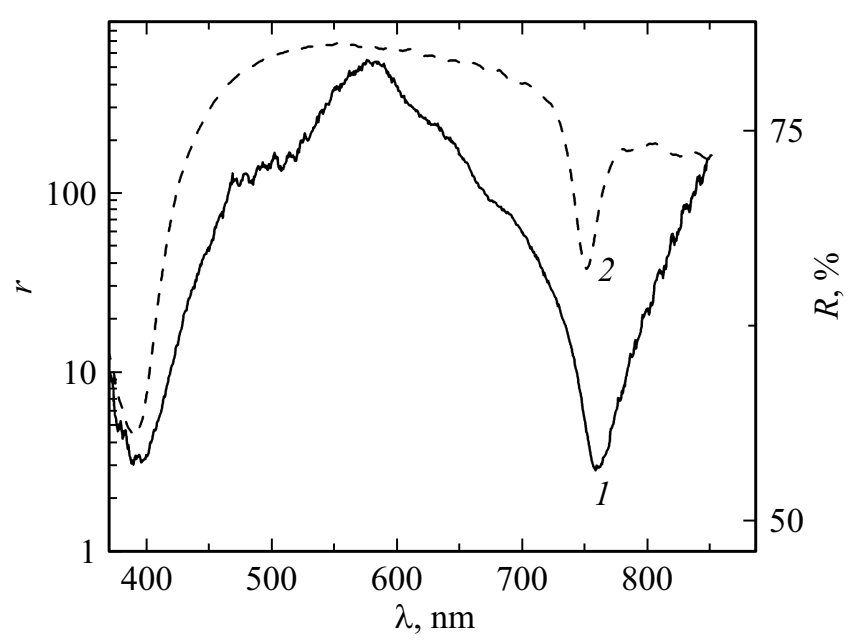

Рис. 4. Спектральная зависимость отношения $r=T_{3}(\lambda) /\left(T_{1}(\lambda) T_{2}(\lambda)\right) \quad(1) \quad$ и $\quad$ спектр отражения $R(\lambda)$ резонатора $\mathrm{Ag} / \mathrm{SiO}_{2} / \mathrm{Ag}(2)$. Угол падения света $\theta=16^{\circ}$. 
бот [36,37] наблюдали эффекты, связанные с возникновением плазмонов на границе Аu-опаловые глобулы, в спектрах отражения и комбинационного рассеяния образцов.

\section{2. Направленное изменение энергетической структуры фотонно-кристаллических материалов посредством введения наноразмерных частиц металла в опаловую матрицу}

Расширения функциональных возможностей металлодиэлектрического образца по управлению потоками ЭМизлучения можно достичь также посредством направленной модификации фотонно-энергетической структуры (ФЭС) нанокомпозита на основе „массивного“ опала. Как известно, металлодиэлектрические системы на основе таких опалов можно создавать путем введения металла в пористую диэлектрическую матрицу. Для этого могут использоваться как химические методы [26,38,39], так и процесс электротермодиффузии [29-32].

Диспергирование различных веществ в регулярной системе полостей опаловых матриц, как правило, приводит к увеличению показателя преломления (ПП) и уменьшению его контраста, что, в свою очередь, вызывает длинноволновый сдвиг максимумов в спектрах брэгговского отражения и уменьшение ширины фотонной запрещенной зоны (ФЗ3) (уширения Ф33 удается достичь обычно лишь в инвертированных опалах) [29].

Наши эксперименты показали, что при малой концентрации наночастиц серебра в опаловой матрице максимумы в спектрах брэгговского отражения демонстрируют стандартный длинноволновый сдвиг. Однако с увеличением плотности тока при введении серебра в опал методом электротермодиффузии наблюдается не только заметный сдвиг максимумов брэгговского отражения фотонного кристалла $\mathrm{Ag} /$ опал в „красную“ область при фиксированных значениях угла падения света, но и значительное уширение полосы в спектре отражения, которая к тому же становится асимметричной (рис. 5, кривые 1 и 2).

Подобный профиль типичен для резонанса Фано [40-43], возникающего вследствие интерференции двух волновых процессов. В данном случае роль одного из них может играть острый брэгговский дифракционный резонанс в ФК, а второй представляет собой широкополосное излучение, рассеянное на случайных дефектах структуры матрицы опала и неоднородностях - дендритах, которые, как показывают электронномикроскопические изображения [29-31], формируются при высокотемпературном электролизе в местах проникновения серебра в опаловую матрицу.

Отметим, что в результате обработки нанокомпозита $\mathrm{Ag} /$ опал в парах иода в некоторых случаях наряду с

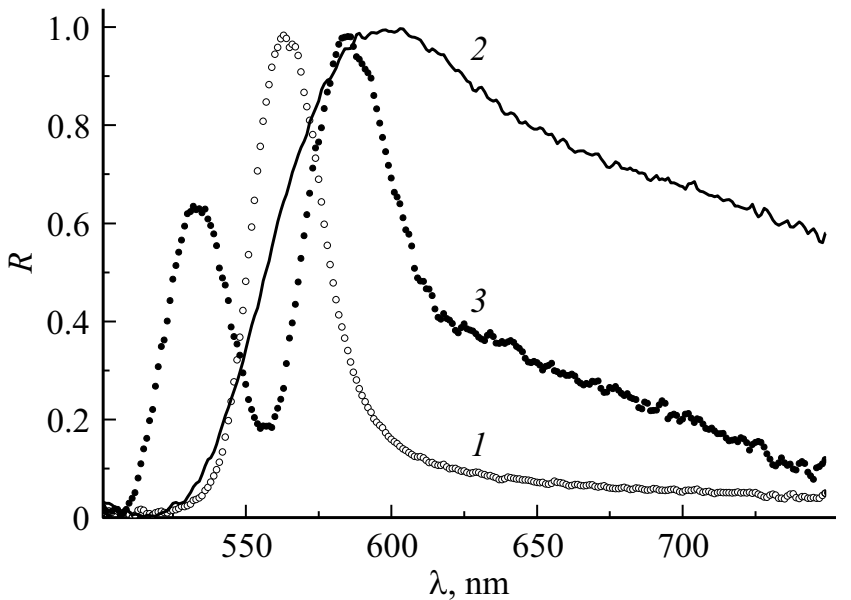

Рис. 5. Нормированные спектры брэгговского отражения при угле падения света $\theta=30^{\circ}: 1-$ исходной опаловой матрицы, 2 - образца нанокомпозита $\mathrm{Ag}$ /опал, полученного методом электротермодиффузии, 3 - образца $\mathrm{Ag} /$ опал после его прогрева в парах йода.

уменьшением ширины и асимметрии длинноволновой полосы в спектре отражения, обусловленной присутствием серебра в нанокомпозите, наблюдается необычный „синий“ сдвиг максимума брэгговского отражения исходного образца опала (рис. 5, кривая 3). Можно предположить, что неоднородность образца $\mathrm{Ag} /$ опал в результате его обработки парами иода существенно увеличивается, так что длинноволновая и коротковолновая полосы, наблюдаемые на кривой 3 (рис. 5), отвечают различным областям образца. При этом основной вклад в „синий“ сдвиг максимума в спектре отражения опаловой матрицы вносит, по-видимому, уменьшение эффективного показателя преломления образца, указывающее на локальное увеличение его пористости.

Этот факт может быть связан с частичным разрушением дендритов в результате взаимодействия металла с парами иода и образованием дополнительных пустот в структуре композиционного материала. Такой коротковолновый сдвиг спектра отражения, который не наблюдается в нанокомпозитах I/опал [44] и AgI/опал [45], предоставляет дополнительные возможности направленной модификации ФЭС композиционного фотонного кристалла на основе опаловой матрицы.

\section{Заключение}

В работе реализованы возможности проектирования на физическом уровне двух типов модельных фотоннокристаллических металлодиэлектрических систем на основе опалов, предназначенных для управления распространением электромагнитного излучения:

1) слоистых структур, полученных последовательным напылением металлических и диэлектрических пленок на монослой опаловых глобул; 
2) нанокомпозитов $\mathrm{Ag} /$ опал на основе „массивных“ опаловых матриц, в которые серебро вводилось методом электротермодиффузии.

Использование опалов в качестве ФК в системах первого типа позволяет технологически достаточно просто обеспечить необходимое соответствие морфологии напыленного металлического покрытия особенностям поверхности исходного ФК, что обеспечивает выполнение условия фазового синхронизма, необходимого для возбуждения ППП на границе раздела металл-диэлектрик. При этом возникает как аномальное оптическое пропускание (ЕОТ), так и аномальное оптическое поглощение (EOA), причем в обоих случаях в спектрах отражения образцов наблюдаются соответствующие минимумы.

В системах второго типа диспергирование серебра в матрице опала модифицировало фотонноэнергетическую структуру системы, что проявилось в уширении и асимметрии полос в спектрах отражения образцов, обусловленных резонансом Фано.

Рассмотренные подходы могут представлять интеpec для разработчиков при создании оптических систем фотоники и наноплазмоники с использованием фотонно-кристаллических материалов с управляемыми свойствами.

\section{Благодарности}

Авторы глубоко признательны В.Л. Вейсману, С.Г. Романову, М.И. Самойловичу, В. Гербредеру, А. Огурцову, У. Пешелю и Д. Плоссу за предоставление образцов для исследования, полезные обсуждения и помощь в проведении экспериментов.

\section{Финансирование работы}

Работа выполнена при частичной финансовой поддержке Российского фонда фундаментальных исследований (РФФИ) в рамках научного проекта № 20-32-90003 и Германской службы академических обменов (DAAD).

\section{Конфликт интересов}

Авторы заявляют, что у них нет конфликта интересов.

\section{Список литературы}

[1] Б.П. Вонг, А. Миттал, Ю. Цао, Г. Старр. Нано-КМОПсхемы и проектирование на физическом уровне (Техноcфepa, M., 2014)

[2] Photonic crystals: Advances in design, fabrication, and characterization. Ed. by $\mathrm{K}$. Busch, S. Lölkes, R.B. Wehrspohn, H. Föll (Wiley-VCH, 2004)

[3] J.D. Joannopoulos, R.D. Meade, J.N. Winn. Photonic Crystals: Molding the Flow of Light (Princeton University Press, 2008)

[4] S.G. Romanov, A. Korovin, A. Regensburger, U. Peschel. Adv. Mater., 23 (22-23), 2515 (2011).

DOI: $10.1002 /$ adma.201100460
[5] Поверхностные поляритоны (Электромагнитные волны на поверхностях и границах раздела сред), под ред. В.М. Аграновича, Д.Л. Миллса (Наука, М., 1985)

[6] K.Y. Bliokh, F.J. Rodríguez-Fortuño, A.Y. Bekshaev, Y.S. Kivshar, F. Nori. Opt. Lett., 43 (5), 963 (2018). DOI: $10.1364 /$ OL.43.000963

[7] Kil-Song Song, Song-Jin Im, Ji-Song Pae, Chol-Song Ri, KumSong Ho, Chol-Sun Kim, Yong-Ha Han. Phys. Rev. B, 102, 115435 (2020). DOI: 10.1103/PhysRevB.102.115435

[8] T. Stauber, A. Nemilentsau, T. Low, G. Gómez-Santos. 2D Materials, 6 (4), 045023 (2019). DOI: $10.1088 / 2053-1583 / \mathrm{ab} 2 \mathrm{f05}$

[9] Д.А. Усанов, А.В. Скрипаль, В.Н. Посадский, В.С. Тяжлов, А.В. Байкин. ЖТФ, 89 (10), 1606 (2019). DOI: 10.21883/JTF.2019.10.48180.619 [D.A. Usanov, A.V. Skripal', V.N. Posadskii, V.S. Tyazhlov, A.V. Baikin. Tech. Phys., 64 (10), 1523 (2019). DOI: $10.1134 / \mathrm{S} 1063784219100232]$

[10] Б.А. Князев, А.В. Кузьмин. Вестник НГУ. Сер. физ., 2 (1), 108 (2007).

[11] S.A. Maier. Plasmonics: Fundamentals and Applications (Springer, NY., 2007)

[12] В.И. Балыкин. УФН, 188 (9), 935 (2018). DOI: $10.3367 / \mathrm{UFNr}$.2017.09.038206

[13] Xingce Fan, Qi Hao, Teng Qiu, Paul K. Chu. J. Appl. Phys., 127, 040901 (2020). DOI: 10.1063/1.5129365

[14] М.Г. Гущин, Д.О. Гагаринова, С.А. Плясцов, Т.А. Вартанян. Опт. и спектр., 129 (9), 1212 (2021). DOI: $10.21883 /$ OS.2021.09.51353.2264-21

[15] S. Ganesan, S. Maricot, J.-F. Robillard, E. Okada, V.T. Bakouche, L. Hay, J.-P. Vilcot. Sensors, 21, 2035 (2021). DOI: $10.3390 / \mathrm{s} 21062035$

[16] Д.В. Нестеренко, Р.А. Павелкин, Ш. Хаяши. Комп. опт., 43 (4), 596 (2019).

DOI: $10.18287 / 2412-6179-2019-43-4-596-604$

[17] P. Li, Y. Wang, P. Xu. Appl. Opt., 58 (16), 4205 (2019). DOI: $10.1364 / \mathrm{AO} .58 .004205$

[18] А.Б. Петрин, О.Д. Вольпян, А.С. Сигов. ЖТФ, $\mathbf{8 8}(3), 433$ (2018). DOI: $10.21883 / \mathrm{JTF}$. 2018.03.45603.2400 [A.B. Petrin, O.D. Vol'pyan, A.S. Sigov. Tech. Phys., 63 (3), 422 (2018). DOI: $10.1134 / \mathrm{S} 1063784218030192]$

[19] Е.А. Кадомина, Е.А. Безус, Л.Л. Досколович. Комп. опт., 42 (5), 800 (2018). DOI: $10.18287 / 2412-6179-2018-42-5-800-806$

[20] В.В. Климов. Наноплазмоника (Физматлит, М., 2010)

[21] В.Я. Ветров, Р.Г. Бикбаев, И.В. Тимофеев. ЖЭТФ, 144 (6), 1129 (2013). DOI: 10.7868/S004445101312002X [S.Y. Vetrov, R.G. Bikbaev, I.V. Timofeev. J. Exp. Theor. Phys., 117, 988 (2013). DOI: 10.1134/S1063776113140185]

[22] А.П. Виноградов, А.В. Дорофеенко, А.М. Мерзликин, А.А. Лисянский. УФН, 180 (3), 249 (2010). DOI: $10.3367 /$ UFNr.0180.201003b.0249

[23] В.Г. Балакирев, В.Н. Богомолов, В.В. Журавлев, Ю.А. Кумзеров, В.П. Петрановский, С.Г. Романов, Л.А. Самойлович. Кристаллография, 38 (3), 111 (1993). [V.G. Balakirev, V.N. Bogomolov, V.V. Zhuravlev, Yu.A. Kumzerov, V.P. Petranovskii, S.G. Romanov, L.A. Samoilovich. Crystallogr. Rep., 38 (3), 348 (1993).]

[24] V.N. Astratov, V.N. Bogomolov, A.A. Kaplyanskii, A.V. Prokofiev, L.A. Samoilovich, S.M. Samoilovich, Yu.A. Vlasov. Il Nuovo Cimento, 17D (11-12), 1349 (1995). 
[25] Г.Н. Алиев, В.Г. Голубев, А.А. Дукин, Д.А. Курдюков, А.В. Медведев, А.Б. Певцов, Л.М. Сорокин, Дж. Хатчисон. ФTT, 44 (12), 2125 (2002). [G.N. Aliev, V.G. Golubev, A.A. Dukin, D.A. Kurdyukov, A.V. Medvedev, A.B. Pevtsov, L.M. Sorokin, J.L. Hutchison. Phys. Solid State, 44 (12), 2224 (2002). DOI: $10.1134 / 1.1529915]$

[26] В.С. Горелик. ФТТ, 51 (7), 1252 (2009). [V.S. Gorelik. Phys. Solid State, 51 (7), 1321 (2009).

DOI: $10.1134 / \mathrm{S} 1063783409070014]$

[27] П.В. Долганов, В.М. Масалов, Н.С. Сухинина, В.К. Долганов, Г.А. Емельченко. ФТТ, 56 (4), 717 (2014). [P.V. Dolganov, V.M. Masalov, N.S. Sukhinina, V.K. Dolganov, G.A. Emel'chenko. Phys. Solid State, 56 (4), 746 (2014). DOI: $10.1134 / \mathrm{S} 1063783414040088]$

[28] E. Armstrong, C. O’Dwyer. J. Mater. Chem. C, 3, 6109 (2015). DOI: $10.1039 / \mathrm{c} 5 \mathrm{tc} 01083 \mathrm{~g}$

[29] А.И. Ванин, Ю.А. Кумзеров, А.Е. Лукин, В.Г. Соловьев, С.Д. Ханин, М.В. Яников. Передача и преобразование электромагнитного излучения в фботоннокристаллических структурах и металлодиэлектрических композиционных системах на основе опалов (Псковский гос. ун-т, Псков, 2017)

[30] A.V. Cvetkov, V.I. Gerbreders, S.D. Khanin, A.E. Lukin, A.S. Ogurcovs, S.G. Romanov, V.G. Solovyev, A.I. Vanin, M.V. Yanikov. Proc. of the $11^{\text {th }}$ Int. Scientific and Practical Conference: Environment. Technology. Resources (Rezekne, Latvia, 2017), v. 3, p. 37. DOI: 10.17770/etr2017vol3.2660

[31] А.И. Ванин, А.Е. Лукин, С.Г. Романов, В.Г. Соловьев, С.Д. Ханин, М.В. Яников. ФТТ, 60 (4), 770 (2018). DOI: 10.21883/FTT.2018.04.45691.06D [A.I. Vanin, A.E. Lukin, S.G. Romanov, V.G. Solovyev, S.D. Khanin, M.V. Yanikov. Phys. Solid State, 60 (4), 774 (2018). DOI: $10.1134 / \mathrm{S} 1063783418040339]$

[32] А.И. Ванин, Ю.А. Кумзеров, С.Г. Романов, В.Г. Соловьев, С.Д. Ханин, А.В. Цветков, М.В. Яников. Опт. и спектр., 128 (12), 1919 (2020). DOI: $\quad 10.21883 / O S .2020 .12 .50330 .156-20$ [A.I. Vanin, Yu.A. Kumzerov, S.G. Romanov, V.G. Solovyev, S.D. Khanin, A.V. Cvetkov, M.V. Yanikov. Opt. Spectr., 128 (12), 2022 (2020). DOI: 10.1134/S0030400X20121078]

[33] С.Г. Романов. ФТТ, 59(7), $1329 \quad$ (2017). DOI: $\quad 10.21883 /$ FTT.2017.07.44597.384 [S.G. Romanov. Phys. Solid State, 59 (7), 1356 (2017). DOI: $10.1134 / \mathrm{S} 1063783417070216]$

[34] А.А. Семенова, А.П. Семенов, Е.А. Гудилин, И.А. Семенова. Изв. РАН. Сер. физ., $83(11), 1553$ (2019). DOI: 10.1134/S0367676519110218 [A.A. Semenova, E.A. Goodilin, A.P. Semenov, I.A. Semenova. Bull. Russian Academ. Sci.: Phys., 83 (11), 1415 (2019). DOI: $10.3103 / \mathrm{S} 1062873819110200]$

[35] М. Борн, Э. Вольф. Основы оптики (Наука, М., 1970)

[36] C. Lethiec, G. Binard, T. Popescu, H. Frederich, P. Ngoc Hong, E. Yraola, C. Schwob, F. Charra, L. Coolen, L. Douillard, A. Maitre1. J. Phys. Chem. C, 120 (34), 19308 (2016). DOI: 10.1021/acs.jpcc.6b05718

[37] Е.В. Панфилова, А.А. Доброносова. Инженерный журнал: наука и инновации, 8, 1 (2017). DOI: $10.18698 / 2308-6033-2017-8-1650$

[38] А.Ф. Белянин, А.С. Багдасарян, С.А. Багдасарян, Е.Р. Павлюкова. Журн. радиоэлектрон., 1, 1 (2021).

DOI: $10.30898 / 1684-1719.2021 .1 .6$
[39] О.В. Андреева, А.И. Сидоров, Д.И. Стаселько, Т.А. Хрущева. ФТT, 54 (6), 1215 (2012). [O.V. Andreeva, A.I. Sidorov, D.I. Stasel'ko, T.A. Khrushcheva. Phys. Solid State, 54 (6), 1293 (2012). DOI: 10.1134/S1063783412060029]

[40] U. Fano. Phys. Rev., 124, 1866 (1961).

[41] M.V. Rybin, A.B. Khanikaev, M. Inoue, K.B. Samusev, M.J. Steel, G. Yushin, M.F. Limonov. Phys. Rev. Lett., 103, 023901 (2009). DOI: 10.1103/PhysRevLett.103.023901

[42] M.V. Rybin, A.B. Khanikaev, M. Inoue, A.K. Samusev, M.J. Steel, G. Yushin, M.F. Limonov. Photon. Nanostruct., 8, 86 (2010).

[43] M.F. Limonov, M.V. Rybin, A.N. Poddubny, Y.S. Kivshar. Nat. Photonics, 11, 543 (2017). DOI: 10.1038/nphoton.2017.142

[44] А.И. Ванин, Ю.А. Кумзеров, В.Г. Соловьев, С.Д. Ханин, С.Е. Ганго, М.С. Иванова, М.М. Прохоренко, С.В. Трифонов, А.В. Цветков, М.В. Яников. ФХС, 47 (3), 299 (2021). DOI: 10.31857/S0132665121030124 [A.I. Vanin, Yu.A. Kumzerov, V.G. Solov'ev, S.D. Khanin, S.E. Gango, M.S. Ivanova, M.M. Prokhorenko, S.V. Trifonov, A.V. Cvetkov, M.V. Yanikov. Glass Phys. Chem., 47 (3), 229 (2021). DOI: 10.1134/S1087659621030123]

[45] A.V. Il'inskii, R.A. Aliev, D.A. Kurdyukov, N.V. Sharenkova, E.B. Shadrin, V.G. Golubev. Phys. Status Solidi A, 203 (8), 2073 (2006). DOI: 10.1002/pssa.200521305 